\title{
Safety of Insertion of Percutaneous Totally Implantable Central Venous Access Devices by Surgical Residents
}

\author{
KEISUKE OBUCHI ${ }^{1}$, KEN IMAIZUMI $^{1}$, HIROYUKI KASAJIMA $^{1}$, MICHIHIRO KURUSHIMA $^{1}$, \\ MINORU UMEHARA ${ }^{1}$, YOUSUKE TSURUGA ${ }^{1}$, DAISUKE YAMANA ${ }^{1}$, KENTARO SATO $^{1}$, \\ AYA SATO $^{1}$, SHINSAKU SUZUKI ${ }^{2}$ and KAZUAKI NAKANISHI ${ }^{1}$ \\ ${ }^{1}$ Department of Gastroenterological Surgery, Hakodate Municipal Hospital, Hakodate, Japan; \\ ${ }^{2}$ Department of Breast Surgery, Hakodate Municipal Hospital, Hakodate, Japan
}

\begin{abstract}
Background/Aim: To compare the outcomes of totally implantable central venous access device (TIVAD) insertions by surgical residents (SRs) with those by experienced surgeons (ESs) and establish the safety of percutaneous TIVAD insertion by SRs. Patients and Methods: A total of 700 insertions were successfully performed between January 2015 and December 2019 in our Department. The puncture site conversion and complication rates were compared, and risk factors related to complications were analysed. Results: In total, 84 and 616 insertions were performed in the SR and ES groups, respectively. SRs mainly punctured the internal jugular vein $(I J V)$, and ESs punctured the subclavian vein (SV). The conversion rate from the IJV to SV was similar, whereas that from the SV to IJV was higher by SRs than ESs. Overall, early, and delayed complications were similar between the two groups. Conclusion: Percutaneous TIVAD inserted into the IJV by an SR was demonstrated to be safe.
\end{abstract}

For three decades since the first report in 1982 (1), totally implantable central venous access devices (TIVADs) have played an important role in providing chemotherapy (2), palliative care (3), and nutritional support (4). TIVADs were shown to reduce overall medical expenditure (5) and risk of complications compared with Hickman catheters $(6,7)$. Since the number of patients with cancer is increasing, we believe that the role of TIVADs will become more significant.

TIVAD insertion can be performed using a percutaneous

This article is freely accessible online.

Correspondence to: Ken Imaizumi, Department of Gastroenterological Surgery, Hakodate Municipal Hospital, 1-10-1, Minatomachi, Hakodate, Hokkaido, 041-8680, Japan.E-mail: imaken1983@gmail.com

Key Words: Percutaneous approach, totally implantable central venous access devices, surgical education, ultrasonography, infection. approach or cut-down manoeuvre. A percutaneous approach for puncturing the central vein with ultrasonographic (US) guidance has a high insertion completion rate but has a high risk of early complications $(8,9)$. In contrast, the overall complication rates of a cut-down manoeuvre for cephalic vein insertion were lower than those of the percutaneous approach (8). However, the cut-down manoeuvre has the disadvantage of a low completion rate $(9,10)$.

TIVAD insertion, which comprises basic surgical techniques, has been considered beneficial for the education of surgical residents (SRs). Few studies have examined the safety of TIVAD insertion focused on the cut-down manoeuvre by SRs $(11,12)$. However, to the best of our knowledge, there have been no studies assessing the safety of a percutaneous approach for SRs performing TIVAD insertions. We believe that the percutaneous method of TIVAD insertion is useful in surgical education. At our hospital, SRs mainly perform TIVAD insertion using a percutaneous approach with real-time US guidance.

We aimed to compare the surgical outcomes of TIVAD insertion between SRs and experienced surgeons (ESs) and verify the safety of percutaneous TIVAD insertion by SRs.

\section{Patients and Methods}

Study setting and patients. This retrospective, single-centre study was approved by the Institutional Review Board of Hakodate Municipal Hospital (Hokkaido, Japan: Reference number 2021-13) and was conducted in accordance with the tenets of the 1964 Declaration of Helsinki and its later amendments. The requirement for informed consent was waived owing to the retrospective nature of this study.

Between January 2015 and December 2019, 702 consecutive TIVAD insertions were performed for 663 patients at our Department. We performed TIVAD insertion for patients planning to receive intravenous chemotherapy, those requiring total parenteral nutrition, and those with difficulty in securing vascular access. Two TIVAD insertions were excluded because they unsuccessfully treated severe hypovolemia. Finally, a total of 700 percutaneous TIVAD insertions were included in this study. All insertions were 
Table I. Baseline characteristics.

\begin{tabular}{|c|c|c|c|c|c|}
\hline Characteristic & & Total $(n=700)$ & $\mathrm{SR}(\mathrm{n}=84)$ & $\mathrm{ES}(\mathrm{n}=616)$ & $p$-Value \\
\hline Patient age, years & Median (range) & $70(18-96)$ & $70(18-96)$ & $71(45-92)$ & 0.95 \\
\hline \multirow[t]{2}{*}{ Gender } & Male & $340(48.6 \%)$ & $41(48.8 \%)$ & $299(48.5 \%)$ & \multirow[t]{2}{*}{$>0.99$} \\
\hline & Female & $360(51.4 \%)$ & $43(51.2 \%)$ & $317(51.5 \%)$ & \\
\hline BMI, $\mathrm{kg} / \mathrm{m}^{2}$, & Median (range) & $20.5(13.1-36.6)$ & $20.6(13.1-35.8)$ & $20.1(13.9-36.6)$ & 0.47 \\
\hline Diabetes mellitus, n (\%) & Yes & $98(14.0 \%)$ & $11(11.9 \%)$ & $74(12.0 \%)$ & 0.62 \\
\hline Antithrombotic, n (\%) & Yes & $103(14.7 \%)$ & $10(11.9 \%)$ & $93(15.1 \%)$ & 0.49 \\
\hline \multirow[t]{4}{*}{ Disease, $\mathrm{n}(\%)$} & Digestive tumour & $340(48.6 \%)$ & $43(51.2 \%)$ & $297(48.2 \%)$ & \multirow[t]{4}{*}{0.24} \\
\hline & HPB cancer & $206(29.4 \%)$ & $17(20.2 \%)$ & $189(30.7 \%)$ & \\
\hline & Breast cancer & $80(11.4 \%)$ & $12(14.3 \%)$ & $68(11.0 \%)$ & \\
\hline & Other & $74(10.6 \%)$ & $12(14.3 \%)$ & $62(10.1 \%)$ & \\
\hline \multirow[t]{3}{*}{ Indication for TIVAD, n (\%) } & Chemotherapy & $617(88.1 \%)$ & $74(88.1 \%)$ & $543(88.2 \%)$ & \multirow[t]{3}{*}{0.80} \\
\hline & TPN & $77(11.0 \%)$ & $9(10.7 \%)$ & $68(11.0 \%)$ & \\
\hline & VA & $6(0.9 \%)$ & $1(1.2 \%)$ & $5(0.8 \%)$ & \\
\hline \multirow[t]{2}{*}{ Puncture site, n (\%) } & IJV & $276(39.4 \%)$ & $72(85.7 \%)$ & $204(33.1 \%)$ & \multirow[t]{2}{*}{$<0.01$} \\
\hline & SV & $424(60.6 \%)$ & $12(14.3 \%)$ & $412(66.9 \%)$ & \\
\hline Postoperative antibiotic drug, n (\%) & Yes & $64(9.1 \%)$ & $3(3.6 \%)$ & $81(13.1 \%)$ & 0.07 \\
\hline Postoperative observation period, days & Median (range) & $253(1-1893)$ & $231(1-1547)$ & $260(1-1893)$ & 0.24 \\
\hline
\end{tabular}

ES: Experienced surgeons; HPB: hepato-pancreatic-biliary; IJV: internal jugular vein; SR: surgical residents; SV: subclavian vein; TIVAD: totally implantable central venous access device; TPN: total parenteral nutrition; VA: vascular access; BMI: body mass index.

divided into two groups depending on the operator: SRs (postgraduate years 1 and 2) and ESs (postgraduate year $\geq 3$ ). All SRs were trained at our Department for at least 2 months of a 2year residency period.

Clinical data were retrospectively collected from hospital databases. Age, sex, body mass index (BMI), comorbidities (diabetes mellitus), administration of antithrombotic therapy, patient diseases, indication for TIVAD insertion, puncture site, administration of postoperative antibiotic drugs, postoperative observational period, and complications were examined in this study. In this study, complications occurring within 24 hours after surgery were defined as early complications, and those occurring after 24 hours were defined as delayed. Early complications included haematoma, arterial puncture, catheter kinking, and pneumothorax; delayed complications included catheter-related bloodstream infection (CRBI), catheter obstruction, catheter fracture, catheter malposition, catheter thrombosis, and port inversion. The postoperative observational period was calculated as the time from the date of insertion to the latest date alive, or date of death, or date of catheter removal due to complications. Infection per 1,000 catheterdays was defined as the number of CRBI events per 1, 000 postoperative observational periods in each group (13).

Percutaneous TIVAD insertion procedures and education of SRs. TIVADs were inserted under local anaesthesia in a fluoroscopic room. During TIVAD insertion, guidelines recommended by the Centers for Disease Control and Prevention were followed (14): Sterile techniques, including nonsterile preparation, handwashing, sterile field/supply preparation, sterile gowning, sterile gloving, and sterile draping. The selection of the venous site to be punctured, the internal jugular vein (IJV) or subclavian vein (SV), was dependent on the operator's decision. However, ESs tended to prefer SV puncture to shorten the subcutaneous tunnelling of the catheter. Using local anaesthesia, all punctures were performed with real-time US guidance, and the position of the catheter was confirmed using
X-ray illumination. The puncture site was converted to another site when venous insertion was difficult at the initial site. A 3-4 cm skin incision was made on the precordia and a subcutaneous pocket in front of the pectoral fascia. Preoperative antibiotics were not administered to all patients. Postoperative antibiotics were administered to some patients who underwent TIVAD by a specific surgeon (15). Conversion cases were included in the initial site for analysis based on an intention to treat.

Most SRs had experience of performing central venous catheter insertions into the IJV. All SRs participated in a learning programme for percutaneous TIVAD insertion at our Department. When ESs performed TIVAD insertion, SRs rigorously observed and helped with the procedure. Subsequently, SRs performed TIVAD insertions and were coached by ESs. After the procedure, SRs received feedback from the ESs. All TIVAD insertions performed by SRs were supervised by ESs for safety. When SRs failed to puncture the vein, ESs punctured the vein, and SRs continued the procedure after the puncture. Patients undergoing such procedures were included in the SR group. Procedure time and blood loss during TIVAD insertion were not usually recorded.

TIVADs used were as follows: MicroNeedle Port, closed-ended 8.0-Fr single-lumen MicroNeedle Port (Covidien Japan, Tokyo, Japan); X-Port isp, closed-ended 8.0-Fr single-lumen Bard X-Port ${ }^{\circledR}$ isp (Bard Access Systems, Salt Lake City, UT, USA); PowerPort M.R.I. isp, open-ended 8.0-Fr single-lumen PowerPort ${ }^{\circledR}$ M.R.I. ${ }^{\circledR}$ isp (Bard Access Systems); and Celsite port, $\mathrm{PU}^{\circledR}$ Celsite ${ }^{\circledR}$ port (Toray Medical, Tokyo, Japan). The choice of TIVAD was dependent on the operator's preference.

Study outcomes. The primary outcome in this study was the difference in postoperative complication rates between the SR and ES groups. The secondary outcomes were the difference in the conversion rate between the SR and ES groups and to identify risk factors related to postprocedural complications. 


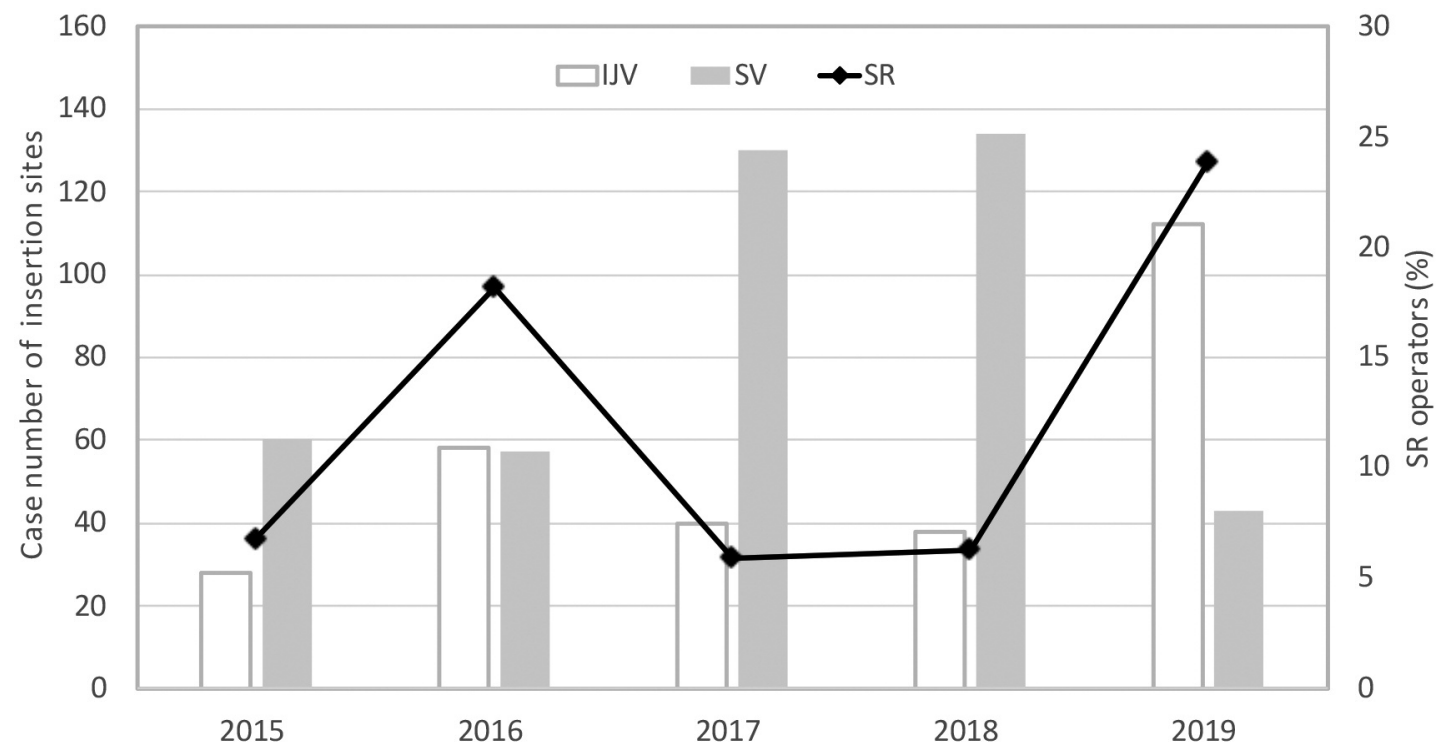

Figure 1. Number of insertion sites for totally implantable central venous access devices and the proportion inserted by surgical resident (SR) operators for each year for the internal jugular and subclavian veins.

Statistical analyses. Fisher's exact test and Student's $t$-test were used to compare patient characteristics and complication rates between the two groups. Risk factors related to complications were analysed using univariate and multivariate logistic regression analyses. Multivariate analysis was performed using variables with $p<0.3$ in the univariate analysis as covariates. A value of $p<0.05$ was considered statistically significant. All statistical analyses were performed using EZR (16) (Saitama Medical Center, Jichi Medical University, Saitama, Japan), which is a graphical user interface for R (The R Foundation for Statistical Computing, Vienna, Austria).

\section{Results}

Patient characteristics. The success rate of TIVAD was $99.7 \%$ (700/702). In total, 84 and 616 TIVAD insertions were performed in the SR and ES groups, respectively. Table I shows patient characteristics for each group. There were no differences between the two groups in patient backgrounds. There was a significant difference in the puncture site between the two groups: the SR group mainly punctured the IJV, while the ES group mainly punctured the SV. Postoperative antibiotic drug administration tended to be higher in the ES group than in the SR group $(p=0.07)$. The postoperative observational period was similar for both the groups. Figure 1 shows the number of TIVAD puncture sites and rate of procedure performed by the SR group for each year. The SV was mainly selected as the puncture site until 2018, and the selection of IJV as the puncture site increased in 2019. Accordingly, TIVAD insertion by SRs increased because of surgical education. Among the 700 TIVADs inserted, $473(67.6 \%), 88(12.6 \%), 77(11.0 \%)$, and 62
(8.8\%) used MicroNeedle Port, X-Port isp, PowerPort M.R.I. isp, and Celsite port, respectively.

Conversion and postoperative complications dependent on puncture site. Table II summarises the conversion and complications in all patients at each puncture site. The puncture site was converted into six insertions (2.2\%) from the IJV to SV and into 15 insertions (3.5\%) from the SV to IJV. Reasons for conversion included failure of puncture in 12 insertions, arterial puncture in seven insertions, and pneumothorax in two insertions. Overall, early, and delayed complication rates considering all patients were $10.4 \%$, $4.7 \%$, and $5.7 \%$, respectively. There were no significant differences in the conversion and postoperative complication rates between the puncture sites (i.e., IJV and SV).

Difference in conversion and postoperative complications between the SR and ES groups. Table III summarises the conversion and complications at each puncture site between the SR and ES groups. The conversion from the IJV to the $\mathrm{SV}$ as puncture site was similar for both groups (1.4\% versus $2.5 \%$, respectively; $p>0.99$ ), whereas that from the SV to IJV was significantly higher in the SR group (25.0\% versus $2.9 \%$, respectively; $p<0.01)$. Overall, early, and delayed complication rates were similar for the two groups. However, the rate of catheter kinking in the SR group was significantly higher $(p=0.03)$. Considering the puncture site, there was no significant difference in catheter kinking in SV puncture between the two groups. In contrast, catheter kinking for puncturing the IJV in the SR group tended to be higher than 
in vivo $36: 985-993(2022)$

Table II. Summary of early, delay and overall complications at each puncture site.

\begin{tabular}{|c|c|c|c|c|c|}
\hline Outcome & & Total $(\mathrm{n}=700), \mathrm{n}(\%)$ & $\operatorname{IJV}(\mathrm{n}=276), \mathrm{n}(\%)$ & $\mathrm{SV}(\mathrm{n}=424), \mathrm{n}(\%)$ & $p$-Value \\
\hline Conversion & Overall & $21(3.0 \%)$ & $6(2.2 \%)$ & $15(3.5 \%)$ & 0.37 \\
\hline Complications & Overall & $73(10.4 \%)$ & $31(11.2 \%)$ & $42(9.9 \%)$ & 0.61 \\
\hline \multirow[t]{5}{*}{ Early* } & Total & $33(4.7 \%)$ & $12(4.3 \%)$ & $21(5.0 \%)$ & 0.86 \\
\hline & Hematoma & $18(2.6 \%)$ & $6(2.2 \%)$ & $12(2.8 \%)$ & 0.64 \\
\hline & Arterial puncture & $7(1.0 \%)$ & $2(0.7 \%)$ & $5(1.2 \%)$ & 0.71 \\
\hline & Kinking in catheter & $6(0.9 \%)$ & $4(1.4 \%)$ & $2(0.5 \%)$ & 0.22 \\
\hline & Pneumothorax & $3(0.4 \%)$ & $0(0 \%)$ & $3(0.7 \%)$ & 0.28 \\
\hline \multirow[t]{7}{*}{ Delayed* } & Total & $40(5.7 \%)$ & $19(6.9 \%)$ & $21(5.0 \%)$ & 0.32 \\
\hline & CRBI & $22(3.1 \%)$ & $7(2.5 \%)$ & $15(3.5 \%)$ & 0.51 \\
\hline & Catheter obstruction & $7(1.0 \%)$ & $5(1.8 \%)$ & $2(0.5 \%)$ & 0.12 \\
\hline & Catheter fracture & $4(0.6 \%)$ & $3(1.1 \%)$ & $1(0.2 \%)$ & 0.31 \\
\hline & Catheter malposition & $4(0.6 \%)$ & $3(1.1 \%)$ & $1(0.2 \%)$ & 0.31 \\
\hline & Catheter thrombosis & $3(0.4 \%)$ & $1(0.4 \%)$ & $2(0.5 \%)$ & $>0.99$ \\
\hline & Inversion of port & $1(0.1 \%)$ & $0(0 \%)$ & $1(0.2 \%)$ & $>0.99$ \\
\hline
\end{tabular}

CRBI: Catheter-related bloodstream infection; IJV: internal jugular vein; SV: subclavian vein. *There is some overlap.

Table III. Summary of the frequency of overall, early and delayed complications at each puncture site and by surgical resident (SR) and experienced surgeon (ES) group.

\begin{tabular}{|c|c|c|c|c|c|c|c|c|c|c|}
\hline \multirow[b]{2}{*}{ Outcome } & & \multicolumn{3}{|c|}{ Total $(\mathrm{n}=700), \mathrm{n}(\%)$} & \multicolumn{3}{|c|}{ IJV (n=276), n (\%) } & \multicolumn{3}{|c|}{$S V(n=424)$} \\
\hline & & $\mathrm{SR}(\mathrm{n}=84)$ & ES $(n=616)$ & $p$-Value & $\operatorname{SR}(n=72)$ & ES $(n=204)$ & $p$-Value & $\operatorname{SR}(n=12)$ & $\mathrm{ES}(n=412)$ & $p$-Value \\
\hline Conversion & Overall & $4(4.8 \%)$ & $17(2.8 \%)$ & 0.30 & $1(1.4 \%)$ & $5(2.5 \%)$ & $>0.99$ & $3(25.0 \%)$ & $12(2.9 \%)$ & $<0.01$ \\
\hline Complications & Overall & $12(14.2 \%)$ & $61(9.9 \%)$ & 0.25 & $9(12.5 \%)$ & $22(10.8 \%)$ & 0.67 & $3(25.0 \%)$ & $39(9.5 \%)$ & 0.11 \\
\hline \multirow[t]{5}{*}{ Early* } & Total & $7(8.4 \%)$ & $26(4.4 \%)$ & 0.10 & $5(6.9 \%)$ & $7(3.4 \%)$ & 0.31 & $2(16.7 \%)$ & $19(4.6 \%)$ & 0.11 \\
\hline & Hematoma & $2(2.4 \%)$ & $16(2.6 \%)$ & $>0.99$ & $2(2.8 \%)$ & $4(2.0 \%)$ & 0.65 & $0(0 \%)$ & $12(2.9 \%)$ & $>0.99$ \\
\hline & Arterial puncture & $1(1.2 \%)$ & $6(1.0 \%)$ & 0.59 & $0(0 \%)$ & $2(1.0 \%)$ & $>0.99$ & $1(8.3 \%)$ & $4(1.0 \%)$ & 0.13 \\
\hline & Kinking in catheter & $3(3.6 \%)$ & $3(0.5 \%)$ & 0.03 & $3(4.2 \%)$ & $1(0.5 \%)$ & 0.06 & $0(0 \%)$ & $2(0.5 \%)$ & $>0.99$ \\
\hline & Pneumothorax & $1(1.2 \%)$ & $2(0.3 \%)$ & 0.32 & $0(0 \%)$ & $0(0 \%)$ & $>0.99$ & $1(8.3 \%)$ & $2(0.5 \%)$ & 0.08 \\
\hline \multirow[t]{7}{*}{ Delayed* } & Total & $5(6.0 \%)$ & $35(5.6 \%)$ & 0.81 & $4(5.6 \%)$ & $15(7.4 \%)$ & 0.79 & $1(8.3 \%)$ & $20(4.9 \%)$ & 0.46 \\
\hline & CRBI & $2(2.4 \%)$ & $20(3.2 \%)$ & $>0.99$ & $2(2.8 \%)$ & $5(2.5 \%)$ & $>0.99$ & $0(0 \%)$ & $15(3.6 \%)$ & $>0.99$ \\
\hline & Catheter obstruction & $0(0 \%)$ & $7(1.1 \%)$ & $>0.99$ & $0(0 \%)$ & $5(2.5 \%)$ & 0.33 & $0(0 \%)$ & $2(0.5 \%)$ & $>0.99$ \\
\hline & Catheter fracture & $2(2.4 \%)$ & $2(0.3 \%)$ & 0.07 & $2(2.8 \%)$ & $1(0.5 \%)$ & 0.17 & $0(0 \%)$ & $1(0.2 \%)$ & 0.24 \\
\hline & Catheter malposition & $1(1.2 \%)$ & $3(0.5 \%)$ & $>0.99$ & $0(0 \%)$ & $3(1.5 \%)$ & 0.57 & $1(8.3 \%)$ & $0(0 \%)$ & 0.03 \\
\hline & Catheter thrombosis & $0(0 \%)$ & $3(0.5 \%)$ & $>0.99$ & $0(0 \%)$ & $1(0.5 \%)$ & $>0.99$ & $0(0 \%)$ & $2(0.5 \%)$ & $>0.99$ \\
\hline & Inversion of port & $0(0 \%)$ & $1(0.2 \%)$ & $>0.99$ & $0(0 \%)$ & $0(0 \%)$ & $>0.99$ & $0(0 \%)$ & $2(0.5 \%)$ & $>0.99$ \\
\hline
\end{tabular}

CRBI: Catheter-related bloodstream infection; IJV: internal jugular vein; SV: subclavian vein. *There is some overlap.

that in the ES group ( $p=0.06)$. In SV puncture, overall and early complications in the SR group were higher than those in the ES group but the difference was not significant. Although there was a significant difference in catheter malposition $(p=0.03)$ in SV puncture, this was due to a single patient in the SR group who developed catheter malposition among 12 patients undergoing SV puncture.

The rate of CRBI was $3.1 \%(22 / 700)$ in patients overall, and there were no significant differences between the two groups. Regarding infections per 1,000 catheter-days for the whole cohort, there were 0.090 infections per 1,000 catheterdays (22 catheter infections in 244,139 catheter-days). The
SR and ES groups developed 0.078 infections per 1, 000 catheter-days (two catheter infections in 25,733 catheterdays) and 0.092 infections per 1,000 catheter-days (20 catheter infections in 218,406 catheter-days), respectively.

Risk factors for complications. Univariate analyses showed that potential risk factors for overall complications were age $\geq 80$ years, BMI $\geq 25 \mathrm{~kg} / \mathrm{m}^{2}$, and $\mathrm{SR}$ operator; for early complications they were age $\geq 80$ years and SR operator; and for delayed complications they were BMI $\geq 25 \mathrm{~kg} / \mathrm{m}^{2}$ and IJV puncture (Table IV). In the multivariate analyses, only BMI $\geq 25 \mathrm{~kg} / \mathrm{m}^{2}$ was identified as an independent significant risk 


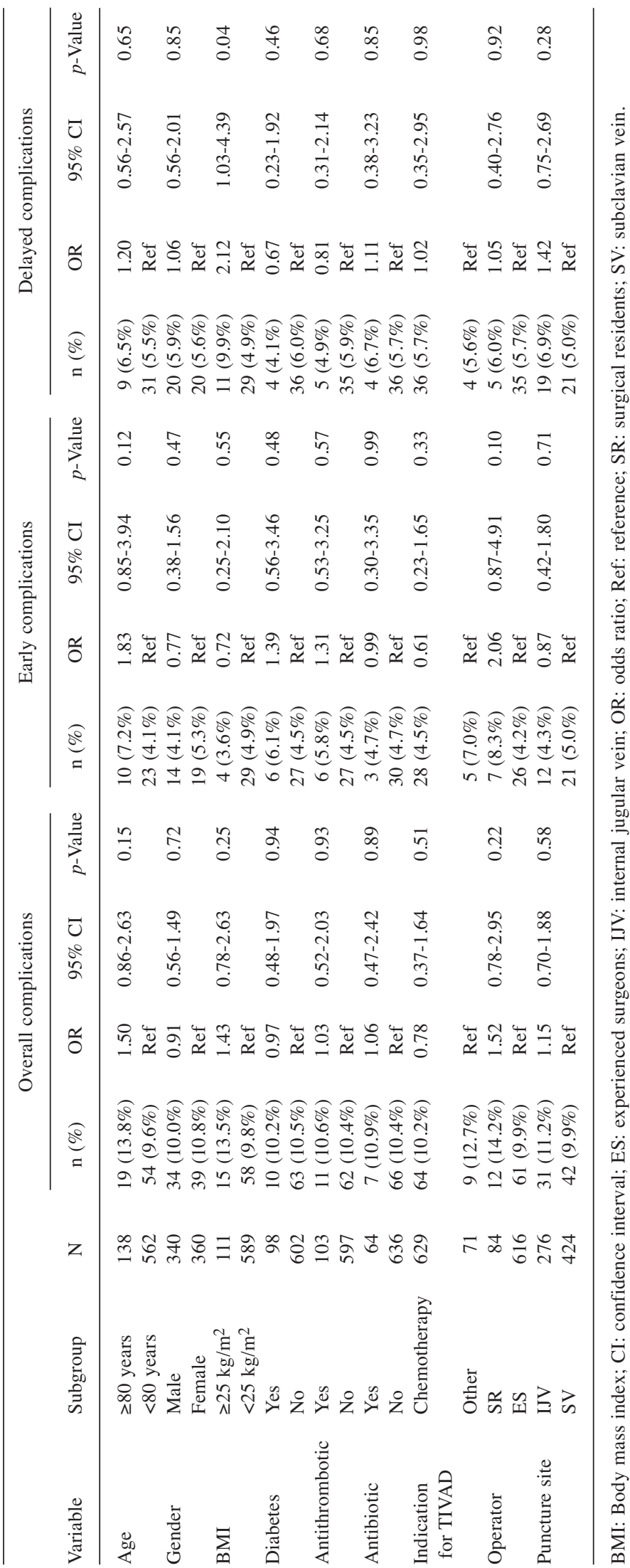


in vivo $36: 985-993(2022)$

Table V. Results of multivariate logistic analysis of risk factors for complications found to be significant in univariate analysis.

\begin{tabular}{|c|c|c|c|c|c|c|c|c|c|c|}
\hline \multirow[b]{2}{*}{ Variable } & \multirow[b]{2}{*}{ Subgroup } & \multicolumn{3}{|c|}{ Overall complications } & \multicolumn{3}{|c|}{ Early complications } & \multicolumn{3}{|c|}{ Delayed complications } \\
\hline & & OR & $95 \% \mathrm{CI}$ & $p$-Value & OR & $95 \% \mathrm{CI}$ & $p$-Value & OR & $95 \% \mathrm{CI}$ & $p$-Value \\
\hline Age & $\begin{array}{l}\geq 80 \text { Years } \\
<80 \text { Years }\end{array}$ & $\begin{array}{c}1.52 \\
\text { Reference }\end{array}$ & $0.87-2.67$ & 0.14 & $\begin{array}{c}1.83 \\
\text { Reference }\end{array}$ & $0.85-3.95$ & 0.12 & & & \\
\hline BMI & $\begin{array}{l}\geq 25 \mathrm{~kg} / \mathrm{m}^{2} \\
<25 \mathrm{~kg} / \mathrm{m}^{2}\end{array}$ & $\begin{array}{c}1.49 \\
\text { Reference }\end{array}$ & $0.81-2.74$ & 0.20 & & & & $\begin{array}{c}2.14 \\
\text { Reference }\end{array}$ & $1.04-4.43$ & 0.04 \\
\hline Operator & $\begin{array}{l}\text { SR } \\
\text { ES }\end{array}$ & $\begin{array}{c}1.54 \\
\text { Reference }\end{array}$ & $0.79-3.02$ & 0.20 & $\begin{array}{c}2.06 \\
\text { Reference }\end{array}$ & $0.86-4.92$ & 0.10 & & & \\
\hline Puncture site & $\begin{array}{l}\text { IJV } \\
\text { SV }\end{array}$ & & & & & & & $\begin{array}{c}1.44 \\
\text { Reference }\end{array}$ & $0.76-2.73$ & 0.27 \\
\hline
\end{tabular}

CI: Confidence interval; ES: experienced surgeons; IJV: internal jugular vein; OR: odds ratio; SR: surgical residents; SV: subclavian vein; BMI: body mass index.

factor for delayed complication (odds ratio $=2.14$, 95\% confidence interval=1.04-4.43; $p=0.04)$. The SR operator was not significantly associated with any complication (Table V).

All patients were divided into subgroups by BMI: $<25$ and $\geq 25 \mathrm{~kg} / \mathrm{m}^{2}$. Details of delayed complications were compared between the two subgroups. The incidence of catheter thrombosis in the $\mathrm{BMI} \geq 25 \mathrm{~kg} / \mathrm{m}^{2}$ group was significantly higher than that in the BMI $<25 \mathrm{~kg} / \mathrm{m}^{2}$ group (Table VI).

\section{Discussion}

Our results showed that for SV puncture, overall and early complication rates in the SR group were relatively higher than that in the ES group. Moreover, site conversion from the SV to IJV was higher in the SR group than that in the ES group. For IJV puncture, there was no significant difference in overall, early, and delayed complications, although SRs needed to be careful to prevent catheter kinking. In the univariate and multivariate analyses of the risk factors, being assigned to the SR group was not significantly associated with overall, early, or delayed complications. To our knowledge, this is the first study to demonstrate the safety of percutaneous TIVAD insertion by SRs.

With the increasing number of patients with cancer, physicians have shown interest in TIVAD insertion using a percutaneous approach (17). The selection of venous sites and approaches for TIVAD have already been discussed in literature (18-22). According to a 27-year comprehensive review of TIVAD insertion, a cut-down manoeuvre was not the predominantly used approach (42.8\%) (18). This approach accounted for only $3.3 \%$ of TIVAD insertions in Japan (23). On the contrary, percutaneous manoeuvres have mainly been selected, among which, SV was the common site used (58.5\%) (18). However, percutaneous US-guided IJV puncture may be a safe alternative approach to SV puncture because it was reported to have a lower risk of major mechanical complications than SV puncture in a
Table VI. Summary of delayed complications according to body mass index $(B M I)$.

\begin{tabular}{lccr}
\hline Complication & $\begin{array}{c}\mathrm{BMI}<25 \\
(\mathrm{n}=589), \mathrm{n}(\%)\end{array}$ & $\begin{array}{c}\mathrm{BMI} \geq 25 \\
(\mathrm{n}=111), \mathrm{n}(\%)\end{array}$ & $p$-Value \\
\hline Total* & $29(4.9 \%)$ & $11(9.9 \%)$ & 0.05 \\
CRBI & $17(2.9 \%)$ & $5(4.5 \%)$ & 0.37 \\
Catheter obstruction & $5(0.8 \%)$ & $2(1.8 \%)$ & 0.31 \\
Catheter fracture & $3(0.5 \%)$ & $1(0.9 \%)$ & 0.50 \\
Catheter malposition & $3(0.5 \%)$ & $1(0.9 \%)$ & 0.50 \\
Catheter thrombosis & $0(0 \%)$ & $3(2.7 \%)$ & $<0.01$ \\
Inversion of port & $1(0.2 \%)$ & $0(0 \%)$ & $>0.99$ \\
\hline
\end{tabular}

CRBI: Catheter-related bloodstream infection. *There is some overlap.

recent meta-analysis (22). Regarding surgical education of TIVAD insertion, a cut-down manoeuvre of the cephalic vein for TIVAD insertion by SRs was reported to be associated with similar complication rates to that performed by ESs (11, 12). As far as we are aware, there have been no reports of surgical education using percutaneous TIVAD insertion.

Generally, a cut-down method for TIVAD insertion has lower complication rates than a percutaneous method. The overall complication rates of cephalic vein cut-down method for TIVAD insertion have been reported to be 4.5-4.6\% (9, 10). The latest meta-analysis has suggested that a cut-down method should be the first-line approach for TIVAD insertion. However, the cut-down method has the disadvantage of a low completion rate (82-92\%) (8-10). The percutaneous approach is generally associated with a relatively higher risk of early complications, such as pneumothorax, haemothorax, or arterial injury, compared with the cephalic vein cut-down method $(8,9)$. In a review of other reports on IJV or SV puncture, the complication rates were as follows: Pneumothorax, <0.1-0.2\% and 1.5$3.1 \%$, respectively; arterial puncture, $6.3-9.4 \%$ and $3.1-4.9 \%$, respectively; and overall complications, $6.3-11.8 \%$ and $6.2-$ 
$10.7 \%$, respectively (19). In our study, the complication rates are equivalent to those reported in several studies $(19,22$, 24-26). Moreover, the completion rate was extremely high $(99.8 \%)$. We believe that TIVAD insertion using the percutaneous approach is better than the cut-down approach for resident's surgical education because the percutaneous technique has a high success rate and is easier to perform than the cut-down technique for SRs.

SV puncture was mainly performed until 2018 in our Department. However, the number of patients who underwent IJV puncture increased in 2019 because SRs had increased surgical training. The proportion of procedures performed by SRs increased from $6.8 \%(6 / 88)$ in 2015 to $23.8 \%(37 / 155)$ in 2019. Our Department has placed particular emphasis on surgical education since 2019 because the number of surgeons in surgical teams has increased. We consider that manpower is required to spend more time on surgical education.

This study has indicated that SRs selected IJV puncture during TIVAD insertion because SV puncture in the SR group was associated with high conversion and complication rates. After SRs acquired sufficient experience in puncturing the IJV with US guidance, they started puncturing the SV. However, the rate of catheter kinking in the SR group was higher than that in the ES group, especially using IJV puncture. ESs should be extra careful when providing instructions to SRs when they perform the tunnelling of the catheter under the skin.

CRBI is a well-known delayed complication of TIVAD insertion. The frequency of CRBI in TIVAD insertion has been reported to range from $6 \%$ to $27 \%(27-29)$, and the infection rate per 1,000 catheter-days ranged from 0.011 to $1.6(6,13,25,30,31)$. Our results were consistent with those of previous reports $(6,13,25,27-31)$. TIVAD insertion by SRs did not increase the incidence of CRBI. Education of residents regarding insertion of a central venous catheter has been reported to reduce the occurrence of CRBI (32). Surgical education may be able to control the occurrence of infections related to TIVAD insertion.

To the best of our knowledge, this is the first study to demonstrate that obesity ( $\mathrm{BMI} \geq 25 \mathrm{~kg} / \mathrm{m}^{2}$ ) is a risk factor for delayed complications and increased risk of catheter thrombosis. The proportion of catheter thrombosis was reported to range from $0.3 \%$ to $28.3 \%$ in a systematic review (33). In previous studies, the risk factors for catheter thrombosis were metastatic breast cancer and left-sided implantation $(34,35)$, but few studies have shown that obesity is a risk factor for thrombosis. In our study, three cases of thrombosis were observed, two for right-sided SV puncture and one for rightsided IJV puncture. Obesity is a major risk factor for deep venous thrombosis (36), and may also be associated with deep venous thrombosis during TIVAD insertion. Patients with a high BMI should be carefully considered for the risk of catheter-related thrombosis as a delayed complication.
Our study has several limitations. Firstly, we retrospectively collected data from a single-centre surgical database and medical records. Secondly, the study had a selection bias. In particular, the puncture site was significantly different between the SR and ES groups because it was selected based on the operator's decision. Thirdly, the data on follow-up outcomes might be insufficient for the assessment of delayed complications because the follow-up period was short in cases of benign disease or subsequent treatment at other hospitals. Fourthly, information on the operative time and blood loss was not available because it was not recorded. Fifthly, the benefits of TIVAD placement on the upper arm have been reported for safety and comfort (37). In this study, use of upper arm TIVAD was not included because there was no case at our Department. We consider that upper arm TIVAD insertion should be examined for the safety of percutaneous TIVAD by SRs. To overcome these limitations, our findings in the present study requires validation in a future prospective study.

In conclusion, our study revealed that TIVAD insertion into the IJV by SRs with real-time US guidance was safe, considering catheter kinking. Although the evidence in this study should be validated in future studies, we believe that these findings will be useful for surgeons' training.

\section{Conflicts of Interest}

The Authors have no conflicts of interest to declare.

\section{Authors' Contributions}

KO, KI, AS, KS, DY, MU, YT, MK, HK, SS, and KN were involved in study design and data interpretation. $\mathrm{KO}$ wrote the article. $\mathrm{KO}$ and $\mathrm{KI}$ were involved in the data analysis. KN supervised the study. All Authors critically revised the report, commented on drafts of the article, and approved the final version.

\section{Acknowledgements}

The Authors gratefully acknowledge the past and present members of the Department of gastroenterological surgery and Department of breast surgery at Hakodate municipal hospital. We would like to thank Editage (www.editage.com) for English language editing.

\section{References}

1 Niederhuber JE, Ensminger W, Gyves JW, Liepman M, Doan K and Cozzi E: Totally implanted venous and arterial access system to replace external catheters in cancer treatment. Surgery 92(4): 706-712, 1982. PMID: 7123491.

2 Decousus H, Bourmaud A, Fournel P, Bertoletti L, Labruyère C, Presles E, Merah A, Laporte S, Stefani L, Piano FD, Jacquin JP, Meyer G, Chauvin F and ONCOCIP Investigators: Cancerassociated thrombosis in patients with implanted ports: a prospective multicenter French cohort study (ONCOCIP). Blood 132(7): 707-716, 2018. PMID: 29980524. DOI: 10.1182/blood2018-03-837153 
3 Taxbro K, Hammarskjöld F, Thelin B, Lewin F, Hagman H, Hanberger $\mathrm{H}$ and Berg S: Clinical impact of peripherally inserted central catheters $v s$. implanted port catheters in patients with cancer: an open-label, randomised, two-centre trial. Br J Anaesth 122(6): 734-741, 2019. PMID: 31005243. DOI: 10.1016/j.bja. 2019.01 .038

4 Santarpia L, Pasanisi F, Alfonsi L, Violante G, Tiseo D, De Simone G and Contaldo F: Prevention and treatment of implanted central venous catheter (CVC) - related sepsis: a report after six years of home parenteral nutrition (HPN). Clin Nutr 21(3): 207211, 2002. PMID: 12127928. DOI: 10.1054/clnu.2002.0541

5 Wu O, Boyd K, Paul J, McCartney E, Ritchie M, Mellon D, Kelly L, Dixon-Hughes J and Moss J: Hickman catheter and implantable port devices for the delivery of chemotherapy: a phase II randomised controlled trial and economic evaluation. Br J Cancer 114(9): 979-985, 2016. PMID: 27092784. DOI: $10.1038 /$ bjc. 2016.76

6 Johansson E, Björkholm M, Björvell H, Hast R, Takolander R, Olofsson P, Backman L, Weitzberg E and Engervall P: Totally implantable subcutaneous port system versus central venous catheter placed before induction chemotherapy in patients with acute leukaemia-a randomized study. Support Care Cancer 12(2): 99-105, 2004. PMID: 14648310. DOI: 10.1007/s00520-0030558-1

7 Patel GS, Jain K, Kumar R, Strickland AH, Pellegrini L, Slavotinek J, Eaton M, McLeay W, Price T, Ly M, Ullah S, Koczwara B, Kichenadasse G and Karapetis CS: Comparison of peripherally inserted central venous catheters (PICC) versus subcutaneously implanted port-chamber catheters by complication and cost for patients receiving chemotherapy for nonhaematological malignancies. Support Care Cancer 22(1): 121128, 2014. PMID: 24005884. DOI: 10.1007/s00520-013-1941-1

8 Matiotti-Neto M, Eskander MF, Tabatabaie O, Kasumova G, Bliss LA, Ng SC, Tawa NE Jr, Murphy B, Critchlow JF and Tseng JF: Percutaneous versus cut-down technique for indwelling port placement. Am Surg 83(12): 1336-1342, 2017. PMID: 29336750.

9 Otsubo R, Hatachi T, Shibata K, Yoshida T, Watanabe H, Oikawa M, Matsumoto M, Yano H, Taniguchi H and Nagayasu T: Evaluation of totally implantable central venous access devices with the cephalic vein cut-down approach: Usefulness of preoperative ultrasonography. J Surg Oncol 113(1): 114-119, 2016. PMID: 26645575. DOI: $10.1002 /$ jso. 24100

10 Povoski SP: A prospective analysis of the cephalic vein cutdown approach for chronic indwelling central venous access in 100 consecutive cancer patients. Ann Surg Oncol 7(7): 496-502, 2000. PMID: 10947017. DOI: 10.1007/s10434-000-0496-9

11 Hashimoto S, Otsubo R, Adachi M, Doi R, Shibata K, Sano I, Shibata Y, Nakazaki T, Taniguchi $\mathrm{H}$ and Nagayasu T: Cephalic vein cut-down for totally implantable central venous access devices with preoperative ultrasonography by surgical residents. In Vivo 33(6): 2079-2085, 2019. PMID: 31662541. DOI: 10.21873/invivo. 11707

12 Schreckenbach T, Münch I, El Youzouri H, Bechstein WO and Habbe N: The safety level of total central venous access port implantation performed by residents. J Surg Educ 76(1): 182192, 2019. PMID: 30120065. DOI: 10.1016/j.jsurg.2018.07.005

13 Biffi R, de Braud F, Orsi F, Pozzi S, Mauri S, Goldhirsch A, Nolè $\mathrm{F}$ and Andreoni B: Totally implantable central venous access ports for long-term chemotherapy. A prospective study analyzing complications and costs of 333 devices with a minimum follow-up of 180 days. Ann Oncol 9(7): 767-773, 1998. PMID: 9739444. DOI: 10.1023/a:1008392423469

14 Berríos-Torres SI, Umscheid CA, Bratzler DW, Leas B, Stone EC, Kelz RR, Reinke CE, Morgan S, Solomkin JS, Mazuski JE, Dellinger EP, Itani KMF, Berbari EF, Segreti J, Parvizi J, Blanchard J, Allen G, Kluytmans JAJW, Donlan R, Schecter WP and Healthcare Infection Control Practices Advisory Committee: Centers for disease control and prevention guideline for the prevention of surgical site infection, 2017. JAMA Surg 152(8): 784791, 2017. PMID: 28467526. DOI: 10.1001/jamasurg.2017.0904

15 Karanlik H, Kurul S, Saip P, Unal ES, Sen F, Disci R and Topuz E: The role of antibiotic prophylaxis in totally implantable venous access device placement: results of a single-center prospective randomized trial. Am J Surg 202(1): 10-15, 2011. PMID: 21601826. DOI: 10.1016/j.amjsurg.2010.05.005

16 Kanda Y: Investigation of the freely available easy-to-use software 'EZR' for medical statistics. Bone Marrow Transplant 48(3): 452-458, 2013. PMID: 23208313. DOI: 10.1038/ bmt.2012.244

17 Bertoglio S, Cafiero F, Meszaros P, Varaldo E, Blondeaux E, Molinelli $\mathrm{C}$ and Minuto M: PICC-PORT totally implantable vascular access device in breast cancer patients undergoing chemotherapy. J Vasc Access 21(4): 460-466, 2020. PMID: 31674857. DOI: $10.1177 / 1129729819884482$

18 Di Carlo I, Pulvirenti E, Mannino M and Toro A: Increased use of percutaneous technique for totally implantable venous access devices. Is it real progress? A 27-year comprehensive review on early complications. Ann Surg Oncol 17(6): 1649-1656, 2010. PMID: 20204533. DOI: 10.1245/s10434-010-1005-4

19 McGee DC and Gould MK: Preventing complications of central venous catheterization. N Engl J Med 348(12): 1123-1133, 2003. PMID: 12646670. DOI: 10.1056/NEJMra011883

20 Liu Y, Li LL, Xu L, Feng DD, Cao Y, Mao XY, Zheng J, Jin F and Chen B: Comparison between arm port and chest port for optimal vascular access port in patients with breast cancer: a systematic review and meta-analysis. Biomed Res Int 2020: 9082924, 2020. PMID: 32104708. DOI: 10.1155/2020/9082924

21 Wu S, Huang J, Jiang Z, Huang Z, Ouyang H, Deng L, Lin W, Guo $\mathrm{J}$ and Zeng W: Internal jugular vein versus subclavian vein as the percutaneous insertion site for totally implantable venous access devices: a meta-analysis of comparative studies. BMC Cancer 16(1): 747, 2016. PMID: 27658952. DOI: 10.1186/ s12885-016-2791-2

22 Narducci F, Jean-Laurent M, Boulanger L, El Bédoui S, Mallet Y, Houpeau JL, Hamdani A, Penel N and Fournier C: Totally implantable venous access port systems and risk factors for complications: a one-year prospective study in a cancer centre. Eur J Surg Oncol 37(10): 913-918, 2011. PMID: 21831566. DOI: $10.1016 /$ j.ejso.2011.06.016

23 Shiono M, Takahashi S, Takahashi M, Yamaguchi T and Ishioka C: Current situation regarding central venous port implantation procedures and complications: a questionnaire-based survey of 11,693 implantations in Japan. Int J Clin Oncol 21(6): 1172-1182, 2016. PMID: 27324107. DOI: 10.1007/s10147-016-1003-Z

24 Araújo C, Silva JP, Antunes P, Fernandes JM, Dias C, Pereira H, Dias T and Fougo JL: A comparative study between two central veins for the introduction of totally implantable venous access devices in 1201 cancer patients. Eur J Surg Oncol 34(2): 222226, 2008. PMID: 17566692. DOI: 10.1016/j.ejso.2007.04.003 
25 Hsieh CC, Weng HH, Huang WS, Wang WK, Kao CL, Lu MS and Wang CS: Analysis of risk factors for central venous port failure in cancer patients. World J Gastroenterol 15(37): 47094714, 2009. PMID: 19787834. DOI: 10.3748/wjg.15.4709

26 Schwarz RE, Groeger JS and Coit DG: Subcutaneously implanted central venous access devices in cancer patients: a prospective analysis. Cancer 79(8): 1635-1640, 1997. PMID: 9118051

27 Vescia S, Baumgärtner AK, Jacobs VR, Kiechle-Bahat M, Rody A, Loibl S and Harbeck N: Management of venous port systems in oncology: a review of current evidence. Ann Oncol 19(1): 915, 2008. PMID: 17846025. DOI: 10.1093/annonc/mdm272

28 Whitman ED and Boatman AM: Comparison of diagnostic specimens and methods to evaluate infected venous access ports. Am J Surg 170(6): 665-9; discussion 669-70, 1995. PMID: 7492023. DOI: 10.1016/s0002-9610(99)80038-5

29 Young C and Gould JR: The timing and sequence of multiple device-related complications in patients with indwelling subcutaneous ports. Am J Surg 174(4): 417-421, 1997. PMID: 9337166. DOI: 10.1016/s0002-9610(97)00145-1

30 Funaki B, Szymski GX, Hackworth CA, Rosenblum JD, Burke $\mathrm{R}$, Chang T and Leef JA: Radiologic placement of subcutaneous infusion chest ports for long-term central venous access. AJR Am J Roentgenol 169(5): 1431-1434, 1997. PMID: 9353475. DOI: 10.2214/ajr.169.5.9353475

31 Park HS, Kim YI, Lee SH, Kim JI, Seo H, Lee SM, Lee Y, Lim MK and Park YS: Central venous infusion port inserted via high versus low jugular venous approaches: retrospective comparison of outcome and complications. Eur J Radiol 72(3): 494-498, 2009. PMID: 19200682. DOI: 10.1016/j.ejrad.2008.09.015

32 Khouli H, Jahnes K, Shapiro J, Rose K, Mathew J, Gohil A, Han Q, Sotelo A, Jones J, Aqeel A, Eden E and Fried E: Performance of medical residents in sterile techniques during central vein catheterization: randomized trial of efficacy of simulation-based training. Chest 139(1): 80-87, 2011. PMID: 20705795. DOI: 10.1378/chest.10-0979
33 Verso $\mathrm{M}$ and Agnelli G: Venous thromboembolism associated with long-term use of central venous catheters in cancer patients. J Clin Oncol 21(19): 3665-3675, 2003. PMID: 14512399. DOI: 10.1200/JCO.2003.08.008

34 El-Balat A, Schmeil I, Karn T, Holtrich U, Mavrova-Risteska L, Rody A, Youssef A and Hanker LC: Catheter-related complications of subcutaneous implantable venous access devices in breast cancer patients. In Vivo 32(5): 1275-1281, 2018. PMID: 30150457. DOI: 10.21873/invivo.11377

35 Ignatov A, Hoffman O, Smith B, Fahlke J, Peters B, Bischoff J and Costa SD: An 11-year retrospective study of totally implanted central venous access ports: complications and patient satisfaction. Eur J Surg Oncol 35(3): 241-246, 2009. PMID: 18329836. DOI: $10.1016 /$ j.ejso.2008.01.020

36 Rosendaal FR: Causes of venous thrombosis. Thromb J 14(Suppl 1): 24, 2016. PMID: 27766050. DOI: 10.1186/s12959016-0108-y

37 Shiono M, Takahashi S, Kakudo Y, Takahashi M, Shimodaira H, Kato $\mathrm{S}$ and Ishioka $\mathrm{C}$ : Upper arm central venous port implantation: a 6-year single institutional retrospective analysis and pictorial essay of procedures for insertion. PLoS One 9(3): e91335, 2014. PMID: 24614412. DOI: 10.1371/journal. pone.0091335
Received December 26, 2021

Revised January 18, 2022

Accepted January 20, 2022 